\title{
Evaluation of Color Models for Palm Oil Fresh Fruit Bunch Ripeness Classification
}

\author{
Nurbaity Sabri ${ }^{1}$, Zaidah Ibrahim ${ }^{2}$, Dino Isa $^{3}$ \\ ${ }^{1}$ Faculty of Computer and Mathematical Sciences, Universiti Teknologi MARA, Campus Melaka, 77300 Melaka \\ ${ }^{2}$ Faculty of Computer and Mathematical Sciences, Universiti Teknologi MARA, Campus Shah Alam, 40450 Selangor \\ ${ }^{3}$ Faculty of Engineering, University of Nottingham Malaysia Campus, Jalan Broga, 43500 Semenyih, Selangor
}

\begin{tabular}{l} 
Article Info \\
\hline Article history: \\
Received Feb 12, 2018 \\
Revised Apr 17, 2018 \\
Accepted Apr 21, 2018 \\
\hline
\end{tabular}

Keywords:

Fresh Fruit Bunch (FFB)

Color models

Color moment

SVM

\begin{abstract}
This paper investigates the application of eight color models for automatic palm oil Fresh Fruit Bunch (FFB) ripeness classification with multi-class Support Vector Machine (SVM). Ripeness classification is important during harvesting to ensure that they are harvested during the correct ripe stage for optimum oil production. Since color is a significant indicator for agriculturists to determine the ripeness of FFB, it is critical to determine the right color model. Eight color models have been investigated namely, HSV, I1I2I3, LAB, XYZ, YCbCr, YIQ, YUV and RGB. Color moments were extracted from each of these color models for the classification of four stages of FFB ripeness that are unripe, under-ripe, ripe and over-ripe. A database of five hundred images of palm oil FFB has been constructed and experiments showed that YCbCr and YUV outperform the other color models.
\end{abstract}

Copyright (c) 2018 Institute of Advanced Engineering and Science. All rights reserved.

\section{Corresponding Author:}

Nurbaity Sabri,

Faculty of Computer and Mathematical Sciences,

Universiti Teknologi MARA, Campus Melaka, 77300 Melaka.

Email: nurbaity_sabri@melaka.uitm.edu.my

\section{INTRODUCTION}

The quality of palm oil Fresh Fruit Bunch (FFB) is important due to high market demands on palm oil products such as consumption, cosmetic industry and many more. One of the main challenges in fruit industry is to identify the right fruit for harvesting. In order to preserve and maintain the quality of palm oil product, it is crucial to harvest palm oil FFB at the right stage. The profit of palm oil industry relies on the post harvesting level [1]. Therefore, by harvesting palm oil FFB at the right phase of maturity, it ensures ideal quality and optimized the amount of oil production. In Malaysia, Elaies Guneensis is the common species of palm oil that is available and mostly planted. The ripeness of this species is determined by Malaysian Palm Oil Board [2]. Table 1 shows some sample images of the four levels of ripeness stages for palm oil FFB. By looking at Table 1, we can see that these different levels of ripeness can be easily determined through color but these color images are influenced by illumination. Thus, it is very challenging to identify the right color since different outdoor lighting condition can affect the color of the images.

Recently, various studies in computer vision for fruit ripeness classification such as watermelon, bananas, and tomatoes have been explored [3]. Most of these studies use color as the parameter to determine the ripeness stage that involves the extraction of useful information concerning the spectral properties of the fruit surface. There are several color models that can be investigated in order to create a reliable approach to classify the fruits into different classes of ripeness [3]. Therefore, selecting an appropriate and accurate color model is crucial for designing and modelling automated machine vision system for palm oil FFB ripeness classification [4].

The most common color model is RGB where any color is described by its intensities of Red (R), Green (G) and Blue (B). RGB values are suitable to be used for constant lighting environment since they are 
affected by changing light intensities [5]. RGB is a typical color model used in many fruit grading research such as peaches [6], mangosteen [7], tomato [8] and avocadoes [9], [10]. RGB color model has been applied in palm oil FFB grading in [11]-[13] but RGB is easily influenced by illumination.

Another color model that is commonly used to classify fruit ripeness is the descriptive parameters Hue, Saturation and Value (HSV) where Hue describes the color; Saturation represents the purity of that color while Value is its brightness. HSV is less affected by illumination changes compared to RGB [14]. HSV is used in [8] to determine the ripeness of tomato by extracting the Hue value from FFB image. In palm oil research, this color model increases the palm oil ripeness classification accuracy by $20 \%$ compared to RGB color model [2].

Table 1. The ripeness stage of palm oil FFB by Malaysian Palm Oil Board [2]

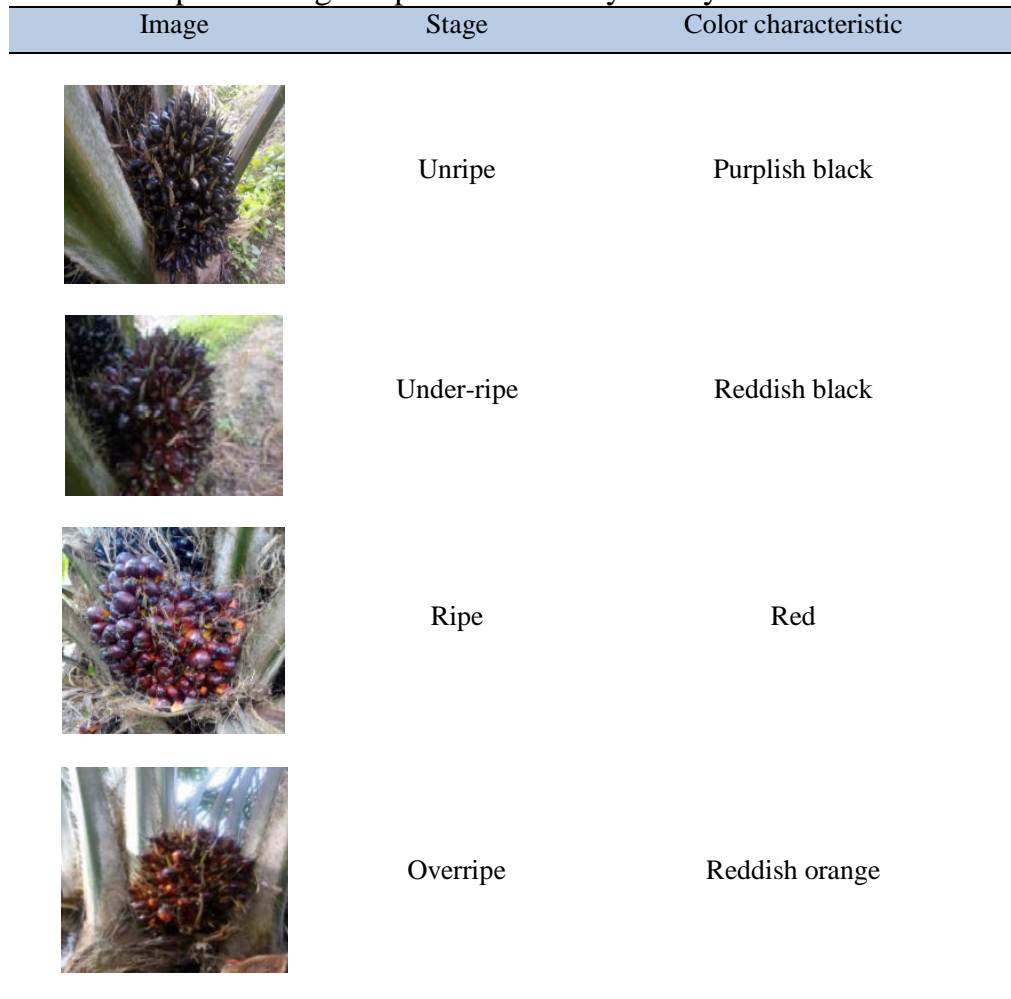

International Commission on Illumination (Commission internationale de l'éclairage) (CIE) Lab color model is associated with display system such as television or color monitor to adapt with human color response characteristics [15]. This color model has been applied ripeness grading of apple and tomato [16], [17]. In palm oil grading, this color model has been used by [2], [11], [18], [19] but at the segmentation stage where this stage removes the noises from the FFB palm oil image. This color model produces a good segmentation result where it manages to remove the unwanted areas in the image.

YCbCr color model commonly use in operation in digital video and image compression [21]. High accuracy has been achieved in classification of ripeness stage for watermelon [19] and orange [22] but moderate for tomato [20] ripeness classification for a least noise background environment. In orange ripeness recognition, lowest error recognition with the most robust algorithm for orange recognition has been recorded [22].

The I1I2I3 color model used in apple detection where it successfully distinguish object form background [23]. In orange recognition, this color model shows a high recognition error compared to other color model [22]. This color model has also been used to recognize dates. However, it produce a moderate result of chrominace component value [24].

The YIQ color model is often used in segmentation operation [25], [26] where Y stores the value of luminance, I stores the value of hue while $\mathrm{Q}$ is for saturation. Besides segmentation, it has also been used for classification purpose such as iris authentication [27], [28]. A comparative study between HSV and YIQ color models for orange fruit grading has shown that YIQ color model is better than HSV [28]. Besides that, 
YIQ color model has also shown high accuracy performance during night environment for litchi recognition [29].

$\mathrm{XYZ}$ model is based on human trigonometric retina and it has been applied on agriculture product classification such as in apple grading system [30] and sorting a citrus fruit [31]. However, this result varies due to the application of different classifiers. It has also been used to reduce the image size or processing time of RGB color model for grading an image of agricultural product indoor and outdoor environment [32].

YUV color model defines a color space in terms of one luma (Y) and two chrominance (UV) and it has less computational time compared to other RGB color model [33]. The color model is closer to human perception rather than the conventional RGB [34]. It has been used in agriculture product where using a single value in YUV is good enough to achieve high classification accuracy such as in oranges and tomato recognition [22], [35].

Since various results have been produced by different color models, an investigation among these reported eight (8) color models is investigated in this paper. The color models are HSV, I1I2I3, LAB, XYZ, YCbRc, YIQ, YUV and RGB. They will be utilized to classify the palm oil FBB ripeness. Researches have been conducted to classify various stages of ripeness for palm oil FBB. According to [2] most of the palm oil grading focuses on two, three or four stages which is unripe, reddish black as underripe, red as ripe, and reddish orange as overripe. Research by [18], [36], [37] focus on two stages which are ripe and unripe of FFB and achieved high accuracy results. [3], [13], [38], [39] recognize three stages of FFB ripeness which is unripe, ripe and overripe while [2], [40] work on four stages which is unripe, underripe, ripe and overripe.

Artificial Neural Network (ANN) has been utilized to classify palm oil FFB into four ripeness stages [2]. However, ANN takes a long processing time due to over-fitting issue. Research on color model evaluation have been done for medical plant identifier using texture features with different classifiers namely Stochastic Gradient Descent (SGD), k-nearest neighbour (kNN), Support vector machine (SVM), Linear Discriminant Analysis (LDA) and Quadratic Discriminant Analysis (QDA) classifiers [41]. SVM produces the best identification result compared to the other classifiers. Thus, this research investigates the performance of the eight color models mentioned earlier for four stages of palm oil FFB ripeness classification with Support Vector Machine (SVM).

This paper is organized as follows: starting with introduction to palm oil FFB and description of each color space used in this research. The next section discusses the various color models evaluated in this research followed by discussions on results analysis. The last section concludes this paper with future work.

\section{RESEARCH METHOD}

\subsection{Transformation from RGB to XYZ}

The values of XYZ are computed using linear transformation from RGB color coordinates as shown in Equation (1).

$$
\left[\begin{array}{l}
X \\
Y \\
Z
\end{array}\right]=\left[\begin{array}{lll}
0.607 & 0.174 & 0.201 \\
0.299 & 0.587 & 0.114 \\
0.000 & 0.066 & 1.117
\end{array}\right]\left[\begin{array}{l}
R \\
G \\
B
\end{array}\right]
$$

\subsection{Transformation from RGB to LAB}

Lab is known as device-independant color model where $\mathrm{L}$ represents the image lightness, *a represents red and green, the blue/yellow coordinates of color-opponent are represented with *b[35]This color model is acquired from XYZ and well known color model according to human color perception system due to comprehensive range of colors and linear representation[35]. Equations (2) to (4) show the calculation of LAB color space.

$$
\begin{aligned}
& L^{*}=116(0.299 R+0.587 G+0.114 B)^{1 / 3}-16 \\
& a^{*}=500\left[\left(1.006(0.607 R+0.174 G+0.201 B)^{1 / 3}-(0.299 R+0.587 G+0.114 B)^{1 / 3}\right]\right. \\
& b^{*}=200\left[(0.299 R+0.587 G+0.114 B)^{1 / 3}-0.846(0.066 G+1.117 B)^{1 / 3}\right]
\end{aligned}
$$

\subsection{Transformation from RGB to YUV}

YUV is known as luminance-chrominance space where it represents one component of luminance and two components of chrominance. The luminance component is represented by $\mathrm{Y}$ produced from XYZ 
color model while luminance of $\mathrm{U}$ and $\mathrm{V}$ are produced from the combination of the $\mathrm{Y}$ component. Equation (5) shows the conversion of RGB to YUV color model.

$$
\left[\begin{array}{l}
Y \\
U \\
V
\end{array}\right]=\left[\begin{array}{ccc}
0.2989 & 0.5866 & 0.1145 \\
-0.147 & -0.289 & 0.436 \\
0.615 & -0.515 & -0.100
\end{array}\right]\left[\begin{array}{l}
R \\
G \\
B
\end{array}\right]
$$

\subsection{Transformation from RGB to $\mathrm{HSV}$}

HSV that is derived from RGB color model presented by Hue, Saturation and Value is a quantification of human color vision. It is widely used and more suitable color space for human eyes. HSL is the alternative color model for HSV where it is represented by H-Hue, S-saturation and L-lightness. Hue $(\mathrm{H})$ is produced by the base color or shadesin the form of degree or number. Saturation (S) is the ratio of white color or brightness of animage. The value (V) represents the lightness of the color where 0 is black and the lightness increases if it is move away from black [42], [26]. Equations (6) to (9) illustrate the transformation from RGB to HSV color spaces:

$$
\begin{aligned}
& H=\operatorname{acros} \frac{\frac{1}{2}(2 R-G-B)}{\sqrt{(R-G)^{2}-(R-G)(G-B)}} \\
& V=\frac{\max (R, G, B)+\min (R, G, B)}{2} \\
& S=\left\{\frac{\max (R, G, B)-\min (R, G, B)}{\max (R, G, B)+\min (R, G, B)}\right\} \text { for } L<0.5 \\
& S=\left\{\frac{\max (R, G, B)-\min (R, G, B)}{2-\max (R, G, B)+\min (R, G, B)}\right\} \text { for } L \geq 0.5
\end{aligned}
$$

\subsection{Transformation from RGB to I1I2I3}

The Intensity-red, Intensity-green, Intensity-blue (I1I2I3) color model was obtained through the decorrelation of the RGB color components using the K-L transform by [43] as in Equation (10). This color model is produced from RGB manipulation. It is usedto highlight the image that contains light effects specifically for glittery object [44].

$$
\left[\begin{array}{l}
I_{1} \\
I_{2} \\
I_{3}
\end{array}\right]=\left[\begin{array}{ccc}
\frac{1}{3} & \frac{1}{3} & \frac{1}{3} \\
\frac{1}{2} & 0 & -\frac{1}{2} \\
-\frac{1}{2} & 1 & -\frac{1}{2}
\end{array}\right]\left[\begin{array}{l}
R \\
G \\
B
\end{array}\right]
$$

\subsection{Transformation from RGB to YIQ}

The YIQ color model where $Y$ represents a luma (brightness of an image used in black and white television) information, $I$ stands for "in-phase” and the $Q$ represents “quadrature" is generated from clockwise rotation of $U$ and V from YUV color model [45]. YIQ color model is generally used in National Television System Committe (NSTC) television standard [26]. This color model is intended to take advantage of human color-response shown in Equation (11).

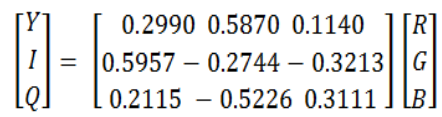

\subsection{Transformation from RGB to YCbCr}

The YCbCrcolor model consists of the Y the luminance component, and description of chrominance component represented byCb and $\mathrm{Cr}$ channels. This color model used in skin color detection due to division of luminance from chrominance [46] as shown in Equations (12) to (14).

$$
\begin{aligned}
& \mathrm{Y}=0.299 \mathrm{R}+0.587 \mathrm{G}+0.114 \mathrm{~B} \\
& \mathrm{Cb}=(\mathrm{B}-\mathrm{Y}) * 0.564+128
\end{aligned}
$$




$$
\mathrm{Cr}=(\mathrm{R}-\mathrm{Y}) * 0.713+128
$$

\section{a) Feature Extraction}

There are many techniques used in color features and among the popular features are color moment [12], [36], [32] and color histogram [2], [22]. A high number of accuracy has been achieved using color moment on palm oil FFB recognition [36]. Therefore, this research implements color moment for color model analysis.

Color moment feature is popular for color detection application due to its ability to deal with lighting and illumination condition specifically for palm oil grading using RGB color image[47].The mean, standard deviation and skewnessfor each color channel is calculated is shown in Equations (11) until (14).

MOMENT 1: Equation (15) finds the average color value of an image where $N$ represents the size of an image in pixels while the Pij represents the pixel intensity according to color channel such as $\mathrm{H} / \mathrm{S} / \mathrm{V}, \mathrm{Y} / \mathrm{I} / \mathrm{Q}$ and $\mathrm{Y} / \mathrm{U} / \mathrm{V}$ in rows and columns.

$$
E i=\sum_{N}^{j=1} \frac{1}{N} P i j
$$

MOMENT 2: Equation (16), $\sigma i$, is also known as the square root of the variance of the color distribution or Standard Deviation where the current pixel is deducted from the mean $E i$ computed in Equation (16). This value is then square root to produce a standard deviation, $\sigma i$.

$$
\sigma i=\sqrt{\left(\frac{1}{N} \sum_{N}^{j=1}(P i j-E i)^{2}\right)}
$$

MOMENT 3: Equation (17), $S i$, for Skewness is a measure of the degree of asymmetry in the distribution. The current pixel is deducted from the mean value, $E i$, and square root of three to produce the skewness, $S i$, value from each color channel.

$$
S i=\sqrt[3]{\left(\frac{1}{N} \sum_{N}^{j=1}(P i j-E i)^{3}\right)}
$$

\section{b) Support Vector Machine (SVM)}

SVM is used to discriminate multiple objects from each other by grouping the attribute of each according object with homogeneous characteristic. It works by separating classes into positive and negative classes by searching for the maximum margin around hyper plane [8]. This research focuses on SVM classification to classify between four stages of FFB using polynomial kernel function.The flow of process of this research is shown in Figure 2. It starts with image acquisition, pre-processing, color feature extraction and classification at the end this process. The result is the classification of the FFB ripeness grading stage that is over-ripe, ripe, unripe or under-ripe.

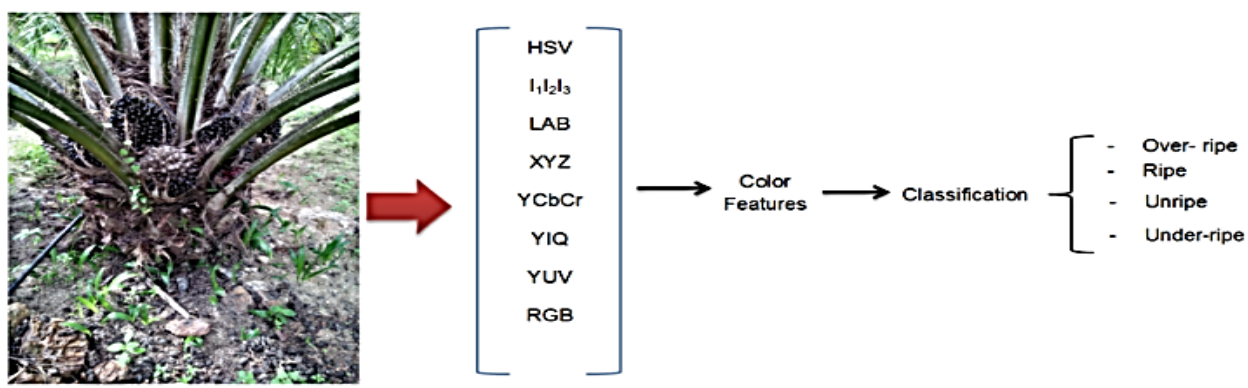

Figure 2. The color model of palm oil FFB ripeness classification process 


\section{c) Data collection}

About 500 palm oil FBB color images were captured by a palm oil expert from an estate located at Batu Pahat, Johor DarulTakzim, Malaysia, that consists of 87 images of over-ripe FFB, 126 images of ripe FFB, 109 images of under-ripe FFB and 147 images of unripe FFB. These images are manually cropped to obtain the region of interest or the FFB area and eliminate the non-FFB areas such as trees, leaves and other objects. These color images are then transformed into 8 types of color models which are HSV, I1I2I3, LAB, XYZ, YCbCr, YIQ, YUV and RGB using the equations explained earlier. Table 2 illustrates some sample images as a result of the 8 color models.

Table 2. Four palm oil FFB ripeness stages with eight color models

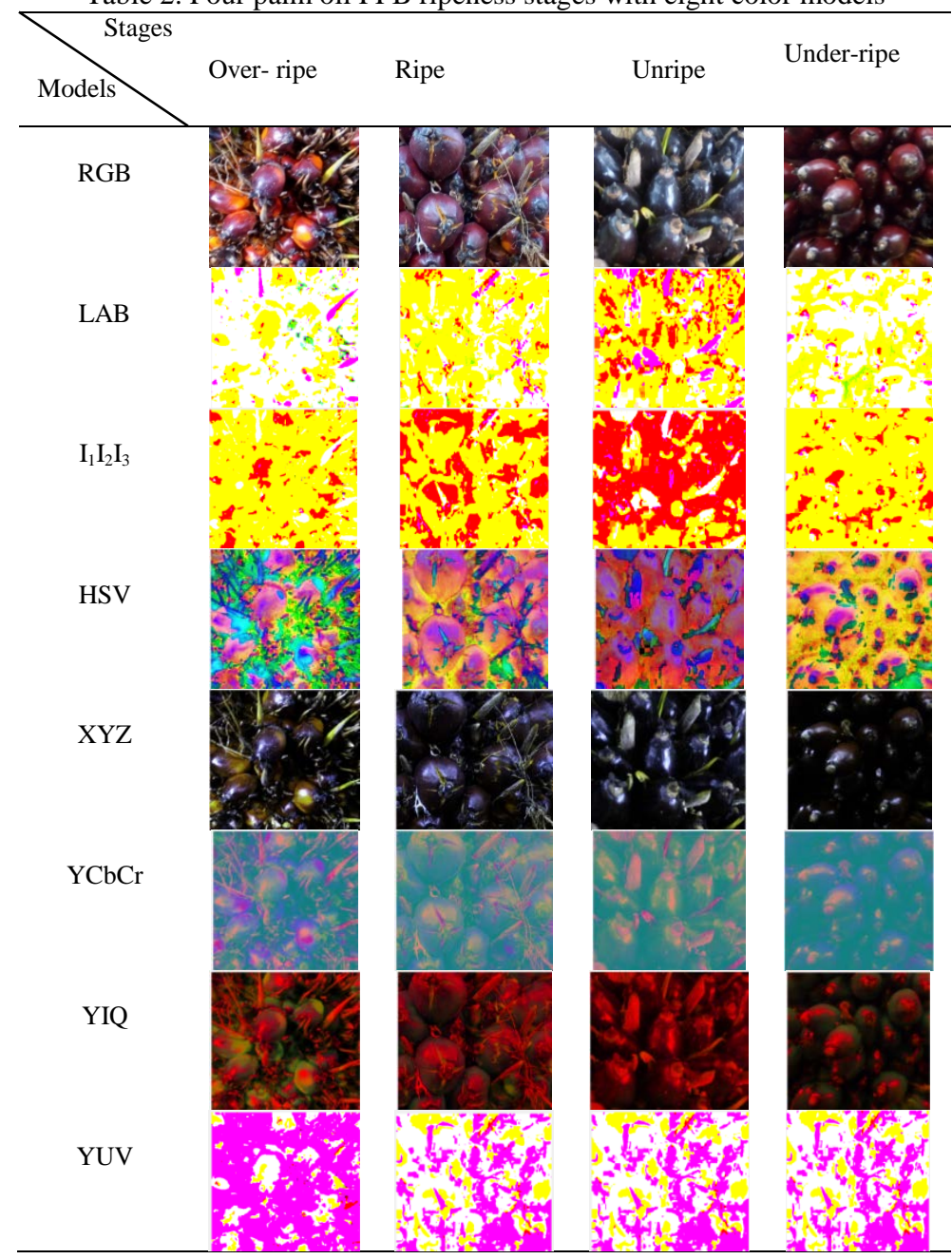

\section{RESULTS AND DISCUSSION}

This experiment is conducted using MATLAB R2016a for feature extraction and Weka for the analysis tool. The data is randomly divided to $80 \%$ training and $20 \%$ testing. Table 3 shows the ripeness classification rate for each color model based on color moment features where it is computed using Equation 14.

$$
\text { Identification rate }=\frac{\text { Correctly identified image }}{\text { total test images }}
$$


Table 3. Result of palm oil ripeness classification rate for the 8 color models

\begin{tabular}{cc}
\hline Color Model & Ripeness Classification rate (\%) \\
\hline HSV & 87.2 \\
I1I2I3 & 85.1 \\
LAB & 97.2 \\
XYZ & 87.2 \\
YCbCr & 98.9 \\
YIQ & 85.6 \\
YUV & $\mathbf{9 8 . 9}$ \\
RGB & 68.6 \\
\hline
\end{tabular}

By observing the results in Table 3, it clearly shows that YCbCr and YUV produce similar ripeness classification rate that is higher than the other color models. It can be concluded that both color models is more robust to illumination compared to other color models. Besides that, it also shows that these color models are less affected with glossiness and silhouette surface of an image compared to other color models. Both of these color models have the same incorrect classification of the overripe images that have been incorrectly classified as under ripe. This may be due to the different number of training data for each stage of ripeness.

RGB color model without transformation shows a slightly low result compared to the other color models. This is due to high correlation between ripe, unripe, over-ripe and under-ripe palm oil FFB images. Besides that, this experiment also shows that the color models with discriminating power such as HSV, LAB and RGB are not associated with the ripeness classification rate.

\section{CONCLUSION}

This paper focuses on the effect of applying different color model for palm oil FFB ripeness classification. Eight color models have been compared in this research which is HSV, I1I2I3, LAB, XYZ, YCbCr, YIQ, YUV and RGB. Four levels of palm oil ripeness has been analyzed which is ripe, unripe, overripe and under-ripe. Each color model has its own characteristic and determination power. YCbCr and YUV color models produce the highest ripeness classification for palm oil FFB. Development of mobile application for ripeness classification will be applied in the future. Besides that, more data will be collected and more comparative study on features extracted from these color models and classifiers will also be conducted in the future.

\section{ACKNOWLEDGEMENT}

This research is financially supported by Institut Pengurusan Penyelidikan dan Inovasi (IRMI), Universiti Teknologi MARA with project code 600-IRMI/DANA 5/3/ARAS (0186/2016).

\section{REFERENCES}

[1] Kamal, M. M., Masazhar, A. N. I., \& Rahman, F. A. (2018). Classification of Leaf Disease from Image Processing Technique. Indonesian Journal of Electrical Engineering and Computer Science, 10(1).

[2] Fadilah, N., Mohamad-Saleh, J., Abdul Halim, Z., Ibrahim, H., \& Syed Ali , S. (2012). Intelligent Color Vision System for Ripeness Classification of Oil Palm Fresh Fruit Bunch. Sensors, 14179-14195

[3] Choong, T. S., Abbas, S., Shariff, A. R., Halim, R., Ismail, M. H. S., Yunus, R., \&Ahmadun, F. R. (2006). Digital image processing of palm oil fruits. International Journal of Food Engineering, 2(2).

[4] D.J. Lee, J.K Archibald, and G.M. Xiong, "Rapid Color Grading for Fruit Quality Evaluation Using Direct Color Mapping,” IEEE Transactions on Automation Science and Engineering, vol. 8/2, p. 292-302, April 2011.

[5] R. Hudzari, W. W. Ishak and M. Norman], Parameter acceptance of software development for oil palm fruit maturity prediction, J. Softw. Eng., vol. 4, 2010, pp. 244-256.

[6] Slaughter, D. C., Crisosto, C. H., \& Tiwari, G. (2013). Nondestructive determination of flesh color in clingstone peaches. Journal of Food Engineering, 116(4), 920e925.)

[7] Palapol, Y., Ketsa, S., Stevenson, D., Cooney, J. M., Allan, A. C., \& Ferguson, I. B. (2009). Colour development and quality of mangosteen (garciniamangostana L.) fruit during ripening and after harvest. Postharvest Biology and Technology, 51(3), 349e353.)

[8] El-Bendary, N., El Hariri, E., Ella Hassanien, A., \&Badr, A. (2015). Using machine learning techniques for evaluating tomato ripeness. Expert Systems with Applications, Volume 42, Issue 4, 1892-1905.

[9] Zhang, Dong, et al. "Date maturity and quality evaluation using color distribution analysis and back projection." Journal of Food Engineering 131 (2014): 161-169.

[10] Guerrero, E. R., \& Benavides, G. M. (2014, June). Automated system for classifying Hass avocados based on image processing techniques. In Communications and Computing. 
[11] Jaffar, A., Jaafar, R., Jamil, N., Low, C. Y., \& Abdullah, B. (2009). Photogrammetric grading of oil palm fresh fruit bunches. Int. J. Mech. Mechatron. Eng, 9, 18-24.

[12] W Budiharto, A Santoso, D Purwanto, A Jazidie. Multiple moving obstacles avoidance of service robot using stereo vision. TELKOMNIKA (Telecommunication, Computing, Electronics and Control). 2011; 9(3): 433-444.

[13] Jamil, N., Mohamed, A., \& Abdullah, S. (2009). Automated Grading of Palm Oil Fresh Fruit Bunches (FFB) using Neuro-Fuzzy Technique. International Conference of Soft Computing and Pattern Recognition.

[14] W. I. W. Ishak and M. H. Razali, Hue optical properties to model oil palm fresh fruit bunches maturity index, World Multi-Conference on Systemics, Cybernetics and Pattern Recognition, 2010.

[15] Wang, Y., Li, W., Pang, S., \& Kan, J. (2013). Segmentation method of Lingwu long jujubes based on L*a* b* color space. Indonesian Journal of Electrical Engineering and Computer Science, 11(9), 5344-5351.

[16] Huang, L., \& He, D. (2012). Ripe fuji apple detection model analysis in natural tree canopy. Indonesian Journal of Electrical Engineering and Computer Science, 10(7), 1771-1778.

[17] Syahrir, W., Suryanti, A., \& Connsynn, C. (2009). Color grading in Tomato Maturity Estimator using image processing technique. Computer Science and Information Technology, 2009. ICCSIT 2009. 2nd IEEE International Conference on.

[18] Roseleena, J., Nursuriati, J., Ahmed, J., \& Low, C. (2011). Assessment of palm oil fresh fruit bunches using photogrammetric grading system. International Food Research Journal, 999-1005.

[19] Shah Rizam, M. S. B., Farah Yasmin, A. R., Ahmad Ihsan, M. Y., \&Shazana, K. (2009). Non-destructive watermelon ripeness determination using image processing and artificial neural network (ANN). International Journal of Electrical and Computer Engineering, 4(6).

[20] Mohamadi , H. M., Alimardani, R., \& Omid, M. (2011). Detection of red ripe tomatoes on stem using Image Processing Techniques. Journal of American Science.

[21] Chaudhary, P., Chaudhari, A. K., Cheeran, D., \& Godara, S. (2012). Color Transform Based Approach for Disease Spot Detection on Plant Leaf. International Journal of Computer Science and Telecommunications .

[22] Hernández-Hernández, J., Hernández-Hernández, M., Feliciano-Morales, S., Álvarez-Hilario, V., \& HerreraMiranda, I. (2017). Search for Optimum Color Space for the Recognition of Oranges in Agricultural Fields. Springer International Publishing, 296-307.

[23] Jidong, L., Wei, J., Fengyi, C., Dean, Z., \& Bo, X. (2012). Research on the Recognition Method for Obscured Apple in Natural Environment. Proceedings of the 31st Chinese Control Conference.

[24] Xiao, A., Li, W., Huang, X., Wang, L., Chai, X., \& Li, C. (2013). The Research Of Detectional Method On Chinese Dates Jiangtou Based On Chrominance Component And Image Morphology. Journal Of Theoretical And Applied Information Technology.

[25] P, G., \& V, R. (2014). YIQ Color Space based Satellite Image Segmentation using Modified FCM Clustering and Histogram Equalization. International Conference on Advance in Electrical Engineering, 1-5.

[26] wichl, K., Shukla, R., \& Shah, A. K. (2017). Color Image Segmentation using FCM Clustering Technique in RGB, L*a*b, HSV, YIQ Color spaces. European Journal of Advances in Engineering and Technology, 194-200.

[27] Narote, A. S., \& Waghmare, L. M. (2017). Color Iris Authentication using Color Models. International Journal of Computer Applications.

[28] Suhasini, A., \& Thendral, R. (2017). Automated skin defect identification system. Current Science.

[29] Xiong , J., Lin , R., Liu , Z., He, Z., Tang, L., Yang, Z., et al. (2017). The recognition of litchi clusters and the calculation of picking point in a nocturnal natural environment. biosystems engineering, 44-57.

[30] Toylan , H., \& Kuscu , H. (2014). A Real-Time Apple Grading System Using Multicolor Space. The Scientific World Journal.

[31]Blasco, J., Aleixos, N., Gómez, J., \& Moltó, E. (2007). Citrus sorting by identification of the most common defects using multispectral computer vision. Journal of Food Engineering, 83(3), 384-393.)

[32] Alfatni, M. S., Mohamed Shariff, A., Abdullah, M., Ben Saeed, O., \& M. Ceesay, O. (2011). Recent Methods and Techniques of External Grading Systems for Agricultural Crops Quality Inspection - Review. International Journal of Food Engineering.

[33] Vyas, A. M., Talati, B., \& Naik, S. (2013). Colour Feature Extraction Techniques of Fruits: A Survey. International Journal of Computer Applications .

[34] Luszczkiewicz-Piatek, M. (2014). Which color space should be chosen for robust color image retrieval based on mixture modeling. Image Processing and Communications Challenges , 55-64.

[35] Chen, X., \& Yang, S. X. (2013). A practical solution for ripe tomato recognition and localisation. Journal of RealTime Image Processing, 35-51.

[36] Sabri, N., Ibrahim, Z., Syahlan, S., Jamil, N., \&Mangshor, N. N. A. (2017). Palm oil fresh fruit bunch ripeness grading identification using color features. Journal of Fundamental and Applied Sciences, 9(4S), 563-579.

[37] A, H., N, S., \& M.A, R. (2017). Application of Integrated AHP and TOPSIS Techniques for Determining the Best Fresh Fruit Bunches (FFB). Journal of Telecommunication Electronic and Computer Engineering.

[38] Mohammed Ben Saeed, O., Sankaran, S., Mohamed Shariff, A., Mohd Shafri, H., Ehsani, R., Alfatni, M. S., et al. (2012). Classification of oil palm fresh fruit bunches based on their maturity using portable four-band sensor system. Computers and Electronics in Agriculture, 55-60.

[39] Hudzari, R., Wan Ishak, W., \& Noorman, M. (2010). Parameter acceptance of software development for oil palm fruit maturity prediction. Journal of Software Engineering, 244-256.

[40] Junaidah, M. J., Norizzah, A. R., Zaliha, O., \& Mohamad, S. (2015). Optimisation of sterilisation process for oil palm fresh fruit bunch at different ripeness. International Food Research Journal, 22(1).

Indonesian J Elec Eng \& Comp Sci, Vol. 11, No. 2, August 2018 : 549 - 557 
[41] Arun, C., \& Durairaj, D. (2017). Identifying Medicinal Plant Leaves Using Textures And Optimal Colour Spaces Channel. Journal of Computer Science and Information, 19-28.

[42] Shipman, J. W. (2012, 10 16). Introduction to color theory. Retrieved 12 21, 2017, from New Mexico Tech: http://infohost.nmt.edu/tcc/help/pubs/colortheory/web/hsv.html

[43] Ohta, Y. I., Kanade, T., \& Sakai, T. (1980). Color information for region segmentation. Computer graphics and image processing, 13(3), 222-241.

[44] Bimbo, A. D. (2016). Resources: MICC Media Integration and Communication Center. Retrieved 12 22, 2017, from MICC Media Integration and Communication Center: https://www.micc.unifi.it/resources/

[45] Plataniotis, K. N., \& Venetsanopoulos, A. N. (2013). Color image processing and applications. Springer Science \& Business Media.

[46] Zaher Hamid Al-Tairi, RahmitaWirzaRahmat, M.IqbalSaripan and PuteriSuhaizaSulaiman , "Skin segmentation using YUV and RGB color spaces” in Journal of Information Processing Systems (JIPS), (2014), pp.283 299

[47] A Muntasa, IA Sirajudin, MH Purnomo. Appearance global and local structure fusion for face image recognition. TELKOMNIKA (Telecommunication, Computing, Electronics and Control).2011; 9 (1): 125-132. 